\title{
FIGURAÇÕES DO FEMININO NA POESIA ERÓTICA DE ALBERTO PIMENTA
}

\author{
Inês Cardoso ${ }^{1}$
}

\begin{abstract}
Resumo: Pensar a erotização do corpo feminino na poesia portuguesa da segunda metade do século XX exige, invariavelmente, a revisitação de uma nova imagem da mulher. Procurando combater o ambiente opressivo que caracterizou a época do Estado Novo, muitas foram as figuras que se implicaram na luta pela democracia e pelos direitos das mulheres, à altura profundamente subjugadas pelo poder patriarcal. Neste contexto, a prática poética apresentou-se como um importante veículo de contestação, espelhando, não raras vezes, uma visão manifestamente libertária da sexualidade feminina e os propósitos de uma luta feminista que apenas poderá ser entendida no seu caráter plural. Assim, partindo das quatro primeiras obras de Alberto Pimenta, cujo processo de escrita coincidiu, em território nacional, com o período de vigência do regime ditatorial, este artigo procura compreender o modo como as figuras femininas surgem num fazer poético no qual o erotismo sempre caminhou a par de uma denúncia que não admite complacências para com uma sociedade profundamente corrompida.
\end{abstract}

Palavras-chave: Alberto Pimenta, poesia portuguesa, poesia erótica, figurações do feminino, erotismo.

\section{REPRESENTATIONS OF THE FEMININE IN THE EROTIC POETRY OF ALBERTO PIMENTA}

\begin{abstract}
In order to contemplate the eroticisation of the female body in Portuguese poetry from the second half of the twentieth century, it is necessary to re-visit the new image of woman. Attempting to fight against the repression that characterized the "Estado Novo" dictatorship, several personalities became involved in the struggle for democracy and women's rights; at that time women were strongly subjugated by the patriarchal power. In this context, poetry represented an important means of rebellion, reflecting a libertarian vision of female sexuality and the purposes of the feminist struggle, which can only be fully understood given its plural nature. Focusing on the first four works of Alberto Pimenta, whose process of writing coincided with the period of the Portuguese dictatorship, this article seeks to understand the way female figures emerge from a poetic practice in which eroticism always appeared in tandem with a callous social criticism.
\end{abstract}

Keywords: Alberto Pimenta, Portuguese poetry, erotic poetry, representations of the feminine, eroticism.

\footnotetext{
${ }^{1}$ Licenciada em Línguas, Literaturas e Culturas pela Faculdade de Letras da Universidade do Porto. Concluiu, na mesma instituição, o Mestrado em Estudos Literários, Culturais e Interartes, com a dissertação intitulada $O$ futuro já mostra que ontem foi há muito tempo: A resistência à globalização em Alberto Pimenta. Integra o Instituto de Literatura Comparada Margarida Losa como investigadora em formação.
} 
Partindo de um princípio de libertação da linguagem, no qual o registo prosaico e vulgar ganha expressividade ao longo de toda a sua produção poética, Alberto Pimenta apresenta-nos uma escrita descomprometida de correlações semânticas que, ao concentrar uma multiplicidade de significações, valida a possibilidade de leituras, entre si tão contraditórias. Este processo de democratização de interpretações não só se revela um fator harmonizador da linguagem do poeta com o universo satiricamente por este convocado, como atesta o princípio vanguardista de contestação e de quebra com o conceito tradicional de literatura. Arrojada, peculiar e muito frequentemente jocosa, a poesia de Pimenta foi desde sempre acolhida por uma minoria. A receção inglória deste fazer poético pode, aliás, ser facilmente compreendida se considerarmos a controvérsia dos temas abordados, bem como o contexto de repressão vivido no decorrer do Estado Novo. Comecemos por recordar, neste sentido, as palavras de Ana Hatherly em "Situação da Vanguarda em Portugal. A Propósito dum Livro de Alberto Pimenta", texto no qual a poeta se debruça sobre a obra Ascensão de dez gostos à boca:

É que a vanguarda artística, de que a literatura de vanguarda é um ramo, chama a si como objectivo de base essa responsabilidade, e por isso os seus cultores se tornam, mais do que ilhas - ("essas ilhas que os autores portugueses são", como escreve J. do Prado Coelho) - isolados, verdadeiros marginais por força das suas ideias e das suas obras, pois umas e outras tentam o assalto (pelo repúdio) do instituído (pelo menos nalgum sector) no domínio das formas, formas que são meio de comunicação e portanto de relação, veiculadoras de história e transformação. (HATHERLY, 1978, p. 57)

É certo que a tentativa de vincular a obra de Alberto Pimenta a qualquer movimento ou corrente estética se revela uma tarefa árdua e, em certa medida, improfícua. Efetivamente, Pimenta estabeleceu diálogos relevantes com os poetas pertencentes ao movimento da Poesia Experimental Portuguesa, partilhando muitas das suas preocupações estéticas. Todavia, se por um lado nos referimos a um período temporal em que Pimenta se encontrava a exercer a função de docente na Universidade de Heidelberg, tomando contacto com as diversas vanguardas europeias e, mais especificamente, com o concretismo alemão, por outro, o poeta desde sempre negou abertamente qualquer tipo vínculo ao movimento. Importa-nos considerar estas questões na medida em que, como sabemos, a Poesia Experimental assumiu um importante papel na luta contra o conservadorismo 


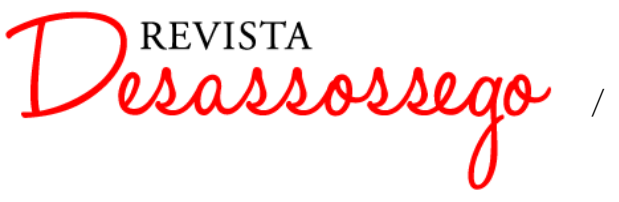

DESASSOSSEGO 17 | JUN/2017 | ISSN 2175-3180

DOI: http://dx.doi.org/10.11606/issn.2175-3180.v9i17p183-197

académico, insurgindo-se face à normatização do ato criativo e reavaliando a tradição sob um prisma de reinvenção. Relembremos, aliás, as palavras de António Aragão:

queremos uma poesia que não explique conteúdos mas forneça estados: donde uma linguagem negra, ausência de estilo e o ataque à fraude da limitação: poesia-contra, poesia-recusa-que-acusa, poesia contra o instituído, o legal, o ordenado e o convencional. poesia da liberdade por estarmos demasiadamente perdidos no cúmulo da condenação. (ARAGÃO, 1981, p. 39)

Embora Alberto Pimenta nunca tenha defendido um estatuto autonómico para a arte, o certo é que também não deixou de reclamar para esta a possibilidade de transgredir as barreiras socialmente impostas. Com efeito, sabemos que o poeta começou a publicar num período no qual a censura se manifestou de um modo absoluto. Porém, não podemos deixar de considerar que nos encontramos perante uma obra que, mesmo após a Revolução de 25 de Abril, se revelou extremamente lúcida face aos perigos de uma censura camuflada - aquela que, ainda hoje, se perpetua através da imposição do discurso dominante. Neste sentido, recordemos a comunicação intitulada $A$ metáfora sinistra, feita em 1988 e que integrou um debate na Semana Cultural da Associação Portuguesa de Escritores, dedicado ao tema "Literatura e Erotismo":

Sinistra ou não, aqui está uma área de investigação à espera de pioneiros. Que a Europa neste caso não tenha razão de dizer que continuamos socraticamente na cauda. Passemos pois para a frente, conscientes de que é aí só que pode acontecer o socialismo verdadeiro, o que de facto reúne capital e trabalho numa mão só, e em que nenhum dos sexos oprima o outro.

Temos eruditos, temos institutos, temos conhecedores da matéria, temos jovens ávidos de aprender. E temos a lei do mecenato. Que é que falta pois? Como sempre, o encorajamento.

Criem-se pois cursos, organizem-se ciclos e grupos de investigação, façam-se palestras, instituam-se bolsas de estudo, alarguem-se as bases, estimulem-se os mais novos: que a masturbação, à semelhança da homossexualidade, e até da heterossexualidade, deixe de ser um segredo acessível só a iniciados. Que deixe de ter segredos! Que se saiba finalmente o que faz a direita e o que faz a esquerda. Que se saiba tudo. Meus senhores e minhas senhoras: mãos à obra! (PIMENTA, 1989, p. 12)

Esta passagem, que de resto finda a própria comunicação, afigura-se exemplificativa de dois pontos essenciais: em primeiro lugar, demonstra como o poeta apresentou, desde 


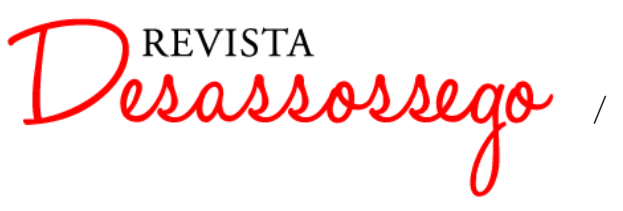

DESASSOSSEGO $17 \quad$ JUN/2017 | ISSN 2175-3180

DOI: http://dx.doi.org/10.11606/issn.2175-3180.v9i17p183-197

sempre, um olhar de condenação face ao estrangulamento do pensamento crítico dentro das comunidades académicas; em segundo, revela o modo como Pimenta se apresentava já muito consciente da luta ingrata que os Estudos Feministas travavam dentro das Universidades. Ora, embora não possamos afirmar que a perspetiva feminista seja um fator primordial do fazer poético de Alberto Pimenta, o certo é que seria imprudente negar a sua existência. $\mathrm{Na}$ realidade, apesar de este artigo se focar em poemas retirados das suas quatro primeiras obras - O labirintodonte (1970), Os entes e os contraentes (1971), Corpos estranhos (1973) e Ascensão de dez gostos à boca $(1977)^{2}$-, a preocupação com questões de género é relativamente constante na sua poesia ${ }^{3}$.

Num artigo publicado em 2003, Maria Irene Ramalho refere que "[Alberto Pimenta] dá voz poética à indignação contra a intolerância, a discriminação, a violência religiosa, racial e sexual, em suma, contra o colonialismo pós-colonial que continua a reger as nossas vidas” (RAMALHO, 2003, p. 10). Esta afirmação parece sintetizar de um modo exímio o propósito desta produção poética, corroborando o poder transformador da palavra num mundo progressivamente mais desumanizado. Já em "Ver-ter-ser", texto originalmente publicado em 1968, E. M. de Melo e Castro afirmava que a vanguarda não "se destina a satisfazer nas suas imediatas necessidades (espirituais ou materiais) nem pobres nem ricos, nem maiorias nem minorias. Serve sim para prospectar, e de certo modo antecipar, o que os homens virão fatalmente a necessitar num futuro mais ou menos próximo" (MELO E CASTRO, 1993, p. 10). Efetivamente, o olhar crítico de Pimenta origina uma obra na qual podemos observar a desconstrução de múltiplos preconceitos, bem como a evidenciação dos vícios intrínsecos a um quotidiano profundamente corrompido. Ao propor uma denúncia fiel das perversões que caracterizam a pósmodernidade, não nos surpreende que este fazer poético possibilite, não raras vezes, o autorreconhecimento. Trata-se de uma poesia perante a qual o leitor, ao confrontar-se com a sociedade em que se insere, caricaturada nas suas mais variadas obsessões, é convidado a refletir e, em última instância, a resistir.

\footnotetext{
${ }^{2}$ Revela-se importante ressalvar que a quarta a obra de Alberto Pimenta, intitulada Ascensão de dez. gostos à boca, foi publicada no ano de 1977, ou seja, após a Revolução de 25 de Abril de 1974. Todavia, o processo de escrita da mesma ocorreu no período compreendido entre 1974 e 1975, justificando a razão pela qual optamos por incluir certos poemas que a compõem.

${ }^{3}$ Recordemos, a título de exemplo, Indulgência Plenária (2007), elegia dividida em cinco partes, na qual Alberto Pimenta procura combater o esquecimento a que Gisberta Salce Júnior permaneceria submetida após o seu bárbaro assassinato, ocorrido em 2006, na cidade do Porto.
} 


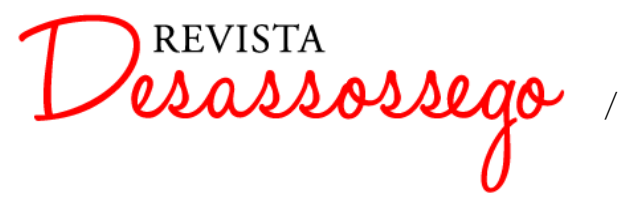

DESASSOSSEGO $17 \quad$ JUN/2017 | ISSN 2175-3180

DOI: http://dx.doi.org/10.11606/issn.2175-3180.v9i17p183-197

Como sabemos, Alberto Pimenta começou a publicar num período em que a tematização do corpo feminino se caracterizava por uma visão manifestamente libertária, sendo as obras de Luiza Neto Jorge e Maria Teresa Horta excelentes exemplos de poéticas de insurreição. De facto, a consciência do papel ativo da mulher - especialmente no âmbito da poesia erótica - obteve, até então, uma maior expressividade na escrita de mulheres. Todavia, não podemos deixar de referir que o ambiente de repressão que caracterizou o período de vigência do Estado Novo teve implicações na visibilidade da produção poética destas escritoras. Como constata Peter Haysom, em Mapeando as "margens de areia": politicas de localização em Novas Cartas Portuguesas:

Em primeiro lugar, no que diz respeito à literatura escrita por mulheres no Portugal pré- 25 de Abril de 1974, é necessário salientar a falta de visibilidade das escritoras em comparação com a atenção pública dada aos escritores. Esta é, aliás, uma situação que remonta aos séculos anteriores. Como salienta Isabel Morujão, apesar de terem existido numerosas autoras portuguesas prolíficas ao longo dos séculos XVIXVIII, nomeadamente dentro dos conventos católicos, o cânone literário nacional continua a negligenciar as escritoras pioneiras da cultura portuguesa[.] (HAYSOM, 2016, p. 35)

Com efeito, torna-se fundamental compreender que nos encontramos perante um regime ditatorial ultra-conservador, no qual imperaram os valores tradicionais de "Deus, Pátria e Família". Trata-se, por isso, de um período fortemente marcado pelo reforço do poder patriarcal e, consequentemente, pela renovação do discurso de domesticidade. Ao pôr em causa a liberdade de todos os cidadãos, a época do Estado Novo caracterizou-se por uma clara perda de autonomia por parte da mulher, que viu o seu acesso a atividades intelectuais e com incidência na esfera pública negado. $\mathrm{Na}$ realidade, como refere Catharina Edfeldt, "nota-se a tendência para silenciar a expressão literária associada às ideias emancipatórias e feministas. Assim, as escritoras, sejam elas assumidamente feministas ou não, passam a ser representadas sobretudo como autoras de literatura infantil" (EDFELDT, 2006, p. 119).

Embora não possamos negar o esforço empreendido por várias mulheres na construção de uma oposição ativa ao regime, o certo é que seria falacioso afirmar a existência de um posicionamento uno e coeso por parte de uma luta feminista singular. Como explica Vanda Gorjão, "[s]ó considerando a oposição feminina e a oposição feminista no plural, podemos aproximar-nos do conhecimento do que foram e fizeram as 


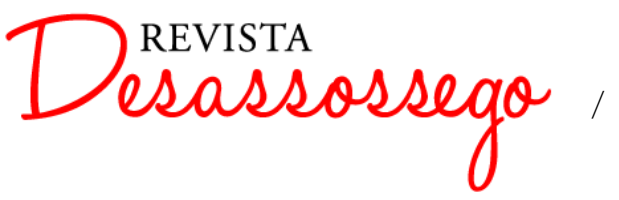

DESASSOSSEGO $17 \quad$ JUN/2017 | ISSN 2175-3180

DOI: http://dx.doi.org/10.11606/issn.2175-3180.v9i17p183-197

muitas mulheres que se implicaram na defesa dos seus direitos" (GORJÃO, 2006, p. 109). Ademais, várias organizações femininas de apoio à ideologia salazarista procuravam assegurar a sustentabilidade do regime ao longo de todo o país, intensificando a divergência de pensamento dentro da própria população do sexo feminino.

Importa-nos considerar esta multiplicidade de perspetivas na medida em que, factualmente, é no cerne da emergência de vozes tão díspares que conseguimos encontrar contributos decisivos para a reconfiguração de uma nova imagem da mulher. Note-se que, ao nível da expressão literária, também Natália Correia, Maria Isabel Barreno e Maria Velho da Costa se apresentam como nomes incontornáveis na luta pelo pensamento democrático, pelos direitos das mulheres e por uma visão manifestamente libertária da sexualidade feminina. Assim, exilado por oposição ao regime fascista português, Alberto Pimenta constitui igualmente uma das vozes que não se deixou silenciar pela censura. Profundamente anticolonialista e anti-imperialista, a obra de Pimenta procurou, em vários momentos, denunciar os estigmas criados em torno do papel social da mulher, reivindicando para esta, no âmbito da sua poesia erótica, o direito à libertação sexual.

Comecemos por recordar que, segundo o poeta, o papel da poesia é dizer o indizivel. Torna-se, por isso, curioso relembrar o ensaio "Erotismo e literatura", no qual o crítico Sebastián Romero-Buj afirma que a literatura produzida no século XX procura expressar o inexpressado:

\begin{abstract}
A literatura contemporânea está a experimentar, em relação às linhas que seguia no século passado, uma mudança que vai desde a sua forma estrutura, linguagem, género - até à sua temática. No seu domínio penetram com violência novos aspectos da vida e dá-se aos velhos um carácter renovado. E tudo isso tendendo para a violência, para a exuberância, para o exagero do devir da existência, visto em conjunto, num conjunto monstruosamente amplificado, como se o escritor aplicasse uma lupa para observar com clareza as coisas que acontecem. Daí que o desejo de surpreender seja um traço saliente das obras aparecidas nos meados deste século. E nós somos surpreendidos não só pelo que nos apresentam como também pela maneira como no-lo apresentam. Porque há nelas uma nova estética, que coincide com uma nova concepção da vida e dos problemas vitais. Sucede que a literatura e a arte parecem expressar o inexpressado. (ROMERO-BUJ, 1979, p. 147)
\end{abstract}

Inegavelmente, Alberto Pimenta representa uma das vozes mais contestatárias e inovadoras da poesia portuguesa contemporânea, não apenas pelas razões anteriormente mencionadas, mas também pelo caráter profundamente eclético da sua vasta produção. De 


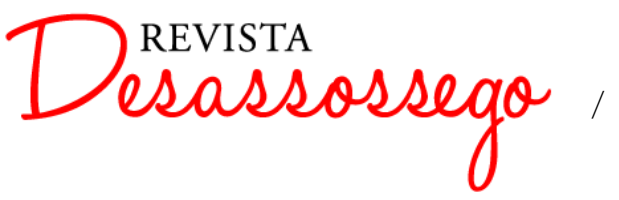

DESASSOSSEGO $17 \quad$ JUN/2017 | ISSN 2175-3180

DOI: http://dx.doi.org/10.11606/issn.2175-3180.v9i17p183-197

facto, esta extensa obra não é apenas constituída por poesia, mas também por vários happenings, performances, atos poéticos, ensaios e textos em prosa. Parece-nos, contudo, exequível afirmar: a denúncia de um mundo no qual é urgente priorizar-se novamente a humanidade apresenta-se como um ponto transversal a todas as formas de expressão enunciadas. Deste modo, não nos surpreende que a poesia erótica de Pimenta surja como um ataque ao conservadorismo e a uma sociedade manifestamente corrompida. Comecemos por atentar no poema "canção de urraca à janela", publicado em 1970:

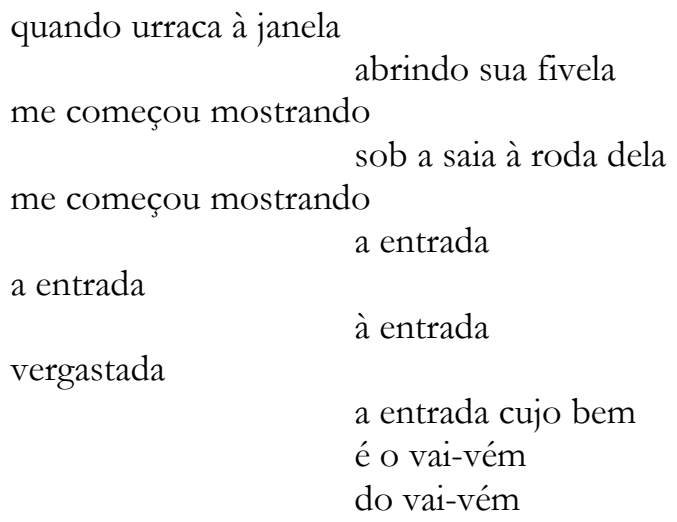

eu libertei-lhe o busto

sem custo (...) (PIMENTA, 1970, p. 12)

Em primeiro lugar, torna-se pertinente reportarmo-nos à análise do poema "Segredo", de Maria Teresa Horta, proposta por Ana Luísa Amaral. A poeta e ensaísta refere a existência de um "cruzamento entre elementos que se inscrevem num campo semântico pertencente a um universo típica (e ancestralmente) feminino (...) e a reivindicação do desejo e desse desejo inscrito num corpo de mulher fortemente erotizado" (AMARAL, 2003, p. 111). Também, em “canção de urraca à janela", verificamos a coexistência de elementos conotados com o ideal de delicadeza - a saia, a fivela - e da negação de uma postura submissa por parte do sujeito feminino. Efetivamente, com base no que alguns versos nos sugerem, poderíamos crer que é a figura masculina que permite a libertação da mulher. Contudo, torna-se interessante constatar como esta parece insurgir-se através da própria ação de seduzir o sujeito poético, já que tal lhe permite reclamar para si mesma um papel ativo.

Apenas um ano mais tarde, o poeta voltou a debruçar-se sobre a imagem feminina, apresentando-nos uma das representações mais sublimes do corpo da mulher alguma vez por si concebidas. "Obra carnal" constitui, nas palavras de Carlos Nogueira, uma "peça 


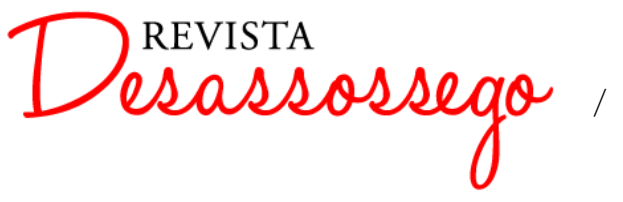

DESASSOSSEGO $17 \quad$ JUN/2017 | ISSN 2175-3180

DOI: http://dx.doi.org/10.11606/issn.2175-3180.v9i17p183-197

partidária da sobre-realidade erótica onde o acto sexual, acompanhado ou não do problemático e indefinível amor espiritual, se traduz na totalidade da sua irreprimível pulsão de psiquismo e de carne" (NOGUEIRA, 2004, p. 455).

Num primeiro momento, Pimenta parte de um registo eufemístico para descrever o órgão sexual feminino: "ajoelha com a cabeça pousada/ de lado as pernas abertas os/ lábios palpitando na orla da/ fresta abrasadora deixando e/ ntrever o claro fundo coralí/ ceo com os joelhos roçando n/ o queixo e abrindo lentament/ e os dedos dos pés" (PIMENTA, 1971, p. 18). Ao propormos uma análise globalizante deste fazer poético, torna-se notório o afastamento de uma poesia que se tendeu a fixar numa linguagem denotativa, originadora de descrições desenfreadas e dotada de um lirismo peculiar. Porém, o final do poema permite-nos novamente o confronto com o espírito libertino tão característico desta obra: "eu vou penetrando de várias/ maneiras ociosamente até sen/ tir a caudelosa corrente de/ bens espraiando-se como a via/ láctea nas negras e eternas/ muralhas do universo visível" (PIMENTA, 1971, p. 18). "Obra carnal” resulta, assim, num espelho do comprazimento sexual, devasso e libidinoso, que não negligenciando o amor espiritual, também não o legitima ou impõe. Recordemos que, segundo Bataille (1988, p. 203), a "sexualidade benéfica está perto da sexualidade animal, por oposição ao erotismo que é específico do homem e só tem de genital a sua origem. O erotismo, em princípio estéril, representa o Mal e o diabólico". Ao compreendermos a sexualidade benéfica enquanto atividade que tem como fim a reprodução, facilmente conseguimos descortinar o princípio libertador deste poema. As fulgurantes imagens cosmológicas apresentadas nos últimos versos revelam, de facto, a visão despreconceituosa do poeta, reafirmando a possibilidade de encarar a sexualidade como um meio para atingir a satisfação pessoal plena.

Propor uma análise da dimensão erótica da poesia de Alberto Pimenta e, por conseguinte, compreender como são traçadas as figuras femininas por si representadas pressupõe o entendimento da dimensão satírica que atravessa toda a sua produção poética. Frequentemente, a pluralidade de estereótipos associada ao universo feminino serve de ponto de partida para a exposição de uma panóplia de valores morais profundamente contaminados. Desta forma, a desconstrução do papel social da mulher, quer pela erotização das suas ações (no mais trivial dos contextos), quer pela criação de uma imagem 


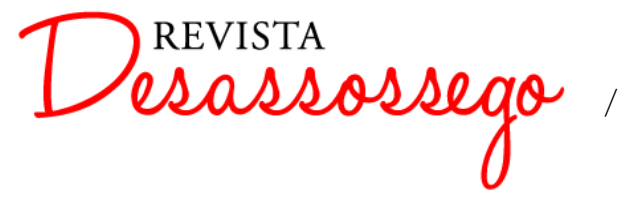

grotesca (aquando da mais corrupta situação), permite que a poesia de Pimenta se afirme como uma denúncia inovadora, simultaneamente jocosa e violenta.

"Espermático" relata-nos, precisamente, um dia comum na vida de uma cozinheira pacata e devota, que prepara minuciosamente uma refeição para servir à família da qual é empregada. "berta" é-nos apresentada como a típica figura feminina proveniente de uma classe humilde, modesta e ingénua, "incapaz de pensar, s/ equer, aquilo que os jovens fazem hoje com/ toda a normalidade, como se de coisas nor/ mais se tratasse!" (PIMENTA, 1973, p. 94). Evidentemente, trata-se de um poema que se estabelece através do imaginário social do Estado Novo - não só espelhado na figura da cozinheira, mas também na do austero "senhor director" e dos "meninos" -, propondo um olhar sobre uma estratificação social na qual a mulher ocupou uma posição subalterna.

Desde logo, importa referir que o processo de estruturação do poema - disposto em nove partes interdependentes, rigidamente organizadas por margens fixas - não é de todo gratuito ou involuntário. Conferindo verticalidade à mancha gráfica, Pimenta cria, como atenta Carlos Nogueira, uma desconcertante "insinuação fálica (...) [que] encontra um correspondente intertextual muito sugestivo nas enguias que 'berta' confecciona para o jantar” (NOGUEIRA, 2004, p. 448). A conotação sexual sugerida por passagens como "puxa-lhe depois a pele para baixo, com um/ pano, com movimentos muito firmes e segura/ ndo-lhe na cabeça com outro pano a fim de a enguia não se esgueirar" (PIMENTA, 1973, p. 95), ou ainda "vai-lhes puxando outra vez a pele para ci/ ma, para o seu primitivo lugar, carregando/ a manteiga para ficar introduzida a maior/ quantidade possível” (PIMENTA, 1973, p. 95) cria, inevitavelmente, uma sensação perturbadora no leitor, que não espera a erotização dos atos de uma figura tão recolhida e pudica. Porém, tal como refere Octavio Paz, a "acção erótica é uma cerimónia que se desenrola para lá das costas da Sociedade e diante de uma natureza que nunca contempla essa representação" (PAZ, 1979, p. 25).

Torna-se também pertinente mencionar que o ideal de mulher religiosa se encontra igualmente desconstruído por Alberto Pimenta. Se num primeiro momento berta se apresenta como devota, que "(...) olha na parede a imagem do papa, do/ santo velhinho" (PIMENTA, 1973, p. 94), no final do poema são os seus "dedos de fada" os agentes de um comportamento considerado profano e evidentemente referido na sua dimensão alegórica. Porém, o questionamento dos valores religiosos e a consequente negação do catecismo 
católico não surgem de forma isolada neste poema. Acentuam-se, aliás, com o crescimento da obra do poeta, conquistando uma faceta reivindicativa de libertação individual, com vista à realização terrena.

Tomemos como exemplo "Carta a uma iniciante", poema no qual o sujeito poético recorre a um posicionamento central de autoridade, excluindo qualquer possibilidade de se deixar retrair pelos postulados doutrinários da Igreja Católica. Dotado de um cariz aparentemente pedagógico, o poema inicia-se com o posicionamento do sujeito num lugar desconhecido, intensificando o seu carácter enigmático:

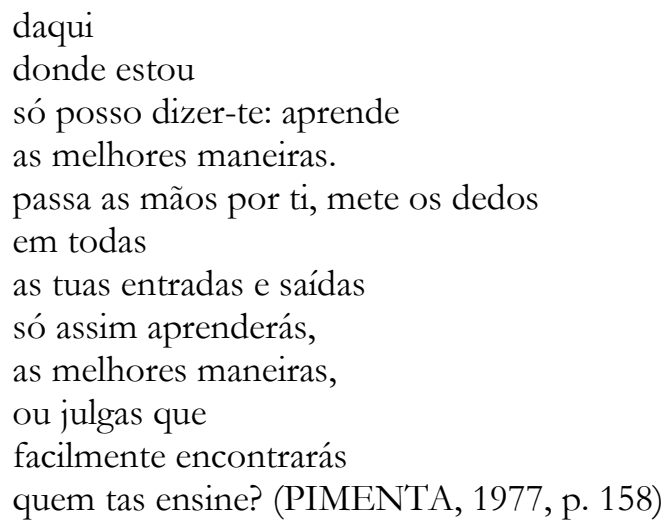

A substituição das "boas maneiras" pelas "melhores maneiras" resulta numa ação de libertação sexual que, ao reclamar a possibilidade de uma realização terrena, visa desassombrar um quotidiano repressor das liberdades individuais. Esta sobreposição das vontades pessoais em relação a um coletivo doutrinalmente regrado pelos pressupostos cristãos encontra o seu apogeu na última estrofe:

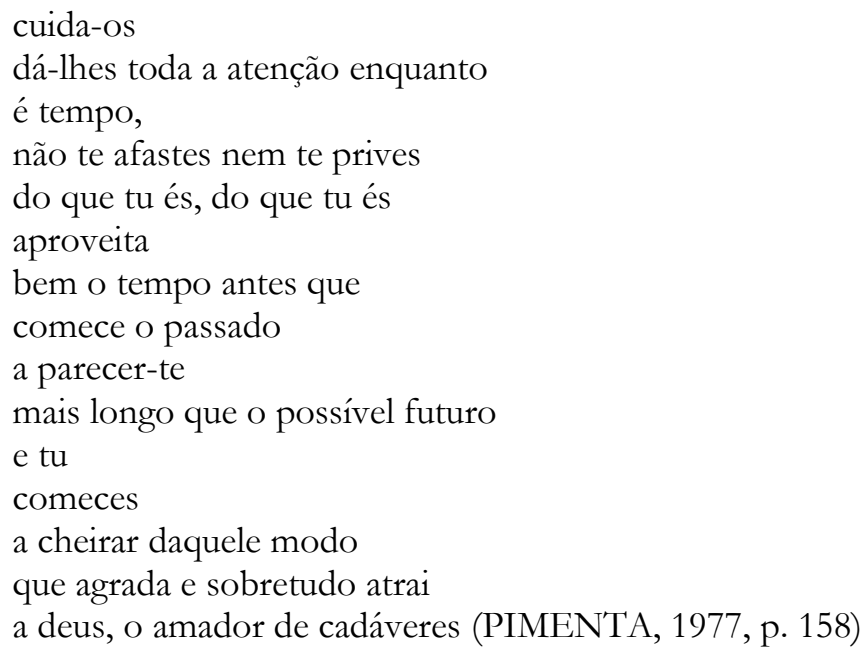


Neste sentido, compreendemos que os apelos do poeta abarcam dois propósitos correlacionados: primeiramente, o objetivo de encarar a sexualidade como algo inerente e natural ao ser humano, rejeitando qualquer estigma de devassidão; em segundo lugar, a negação de uma vida terrena regida pelo pressuposto da contenção. O conhecimento e a realização plena emergem então relevados como os pontos fulcrais a alcançar antes da chegada de "deus, o amador de cadáveres", questionando-se assim os conceitos de bem e mal e desmistificando-se a velha máxima de que um sistema de regras condiciona o destino após a morte. No fundo, podemos afirmar que o caráter transgressivo deste poema assenta, precisamente, na diluição do secretismo e das inibições que assombram a liberdade sexual. Em $O$ erotismo, Georges Bataille debruça-se, aliás, sobre o paradoxo subjacente à noção de proibição:

O que é notável na proibição sexual é que esta só se revela plenamente na transgressão. A educação revela-nos um aspecto dela, mas nunca resolutamente formulado. A educação, com efeito, procede tanto por silêncios como por advertências encapotadas. É directamente pela descoberta furtiva - que começa por ser parcial -, no domínio proibido, que a proibição nos aparece. No começo, nada é mais misterioso. Somos admitidos ao conhecimento dum prazer no qual a noção de prazer se confunde com a de mistério, expressivo da proibição que determina o prazer ao mesmo tempo que o condena. (BATAILLE, 1988, p. 94)

Com efeito, o pressuposto de que o ato de transgressão origina e intensifica o prazer encontra-se igualmente patente nos versos "repara/ como todos/ te querem ensinar/ as boas maneiras/ mas já alguém te/ falou das melhores?” (PIMENTA, 1977, p. 158). Ademais, ao dirigir-se a uma entidade feminina, "Carta a uma iniciante" apresenta-se como uma crítica intensa à opressão vivenciada pelas mulheres face à possibilidade de explorarem a sua sexualidade, hipótese perspetivada até muito tarde como algo dissoluto. Deste modo, a poesia de Alberto Pimenta não só confere à mulher o estatuto de sujeito desejante como reivindica para esta - no contexto de um mundo regido por valores androcêntricos - uma liberdade que lhe foi moralmente negada durante vários séculos.

Esta ampla denúncia dos vícios que definem a sociedade contemporânea contempla ainda uma visão acerca do recôndito universo das casas de prostituição, temática que se encontra desconcertantemente explorada no poema "coroamento". Atentando no irónico verso "as senhoras e os senhores imaginam uma pensão" (PIMENTA, 1973, p. 56), 


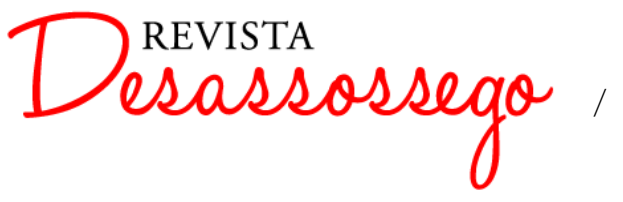

DESASSOSSEGO $17 \quad$ JUN/2017 | ISSN 2175-3180

DOI: http://dx.doi.org/10.11606/issn.2175-3180.v9i17p183-197

compreendemos que o poeta define, a priori, o alvo a quem se dirige, adotando desde logo um registo iminentemente crítico. Deste modo, torna-se curioso verificar que este ataque se intensifica progressivamente, encontrando o seu expoente máximo em versos como "(...) todos esses homens são senhoritos e senhore/ cos, tudo senhoritos e senhorecos" (PIMENTA, 1973, p. 58). Alberto Pimenta adota, assim, um realismo descritivo mordaz e violento, a fim de denunciar uma prática que, ao encontrar-se permanentemente envolvida numa aura de secretismo, não é um facto socialmente desconhecido. Carlos Nogueira refere-se, aliás, a este poema como uma "tematização de um quadro comportamental, sociobiológico, com foros de universalidade profundamente enraizada na cultura de todos os povos" (NOGUEIRA, 2004, p. 453).

Este registo controverso regula igualmente a descrição da imagem feminina perspetivada. Passagens como "fontes de infecções, de tumores, de septicémias,/ as mulheres ficam a sangrar durante semanas" (PIMENTA, 1973, p. 57), ou "porque os homens que para aí andam e acendem o/ cigarro de mão em concha, já ao olhar para as mulheres parecem estar a emprenhá-las, a perfurá/ las (...)” (PIMENTA, 1973, p. 58) sugerem-nos uma visão masculina degradante do sujeito feminino, aqui representado enquanto objeto de satisfação sexual. Porém, torna-se curioso verificar o modo como a repulsa experienciada pelo leitor surge irrisoriamente aniquilada pelo incidente ocorrido ao indivíduo que se dirige a esta "pensão que aluga quartos à hora, à meia-ho/ ra (...)" (PIMENTA, 1973, p. 56). É possível constatar que o estatuto animalesco do homem, bem como o papel submisso atribuído à mulher, se encontram eximiamente desconstruídos:

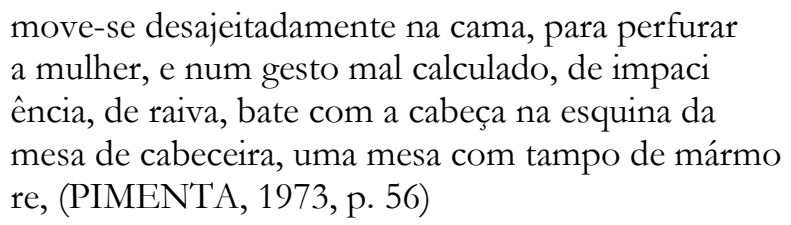

Esta jocosa descrição do acidente não se confina, todavia, aos versos mencionados. $\mathrm{Na}$ realidade, surge detalhadamente desenvolvida ao longo de todo o poema, resultando num discurso que não apresenta qualquer complacência para com o morto:

o homem bateu com a testa na esquina da mesa e o sangue não queria parar. A mulher levantou se e ficou-o olhando por instantes e, não exa gero, se acrescentar que ela urinou, se urinou 


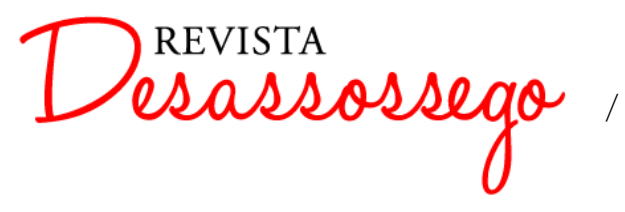

DESASSOSSEGO $17 \quad$ JUN/2017 | ISSN 2175-3180

DOI: http://dx.doi.org/10.11606/issn.2175-3180.v9i17p183-197

levemente, pelas pernas abaixo, e num leve es

guicho, que caiu na testa do morto. (PIMENTA, 1973, p. 59)

Deste modo, compreendemos que a última estrofe emerge como o ponto culminante de uma das críticas mais severas que Alberto Pimenta produziu. Como refere novamente Carlos Nogueira, “a troca de substâncias líquidas (o fluido feminino não é o esperado, nem o mais dignificante) efectiva-se, portanto, numa constrangida fusão" (NOGUEIRA, 2004, p. 14). Indubitavelmente, os versos que findam o poema vêm corroborar a negação do princípio de supremacia masculina, desconstruindo a hierarquização de poder sugerida num momento inicial.

No entanto, torna-se relevante mencionar que uma similar visão grotesca do feminino é-nos também oferecida por “(...) aquela que/ por ser tão pobrezinha teve/ que remendar o vestido à luz/ duma lâmpada muito fraquinha” (PIMENTA, 1977, p. 58). Referimo-nos a "O milagre de joaninha”, poema que apesar de não apresentar um caráter marcadamente erótico, pode estabelecer pontos de contacto interessantes com "coroamento".

Assim, torna-se possível constatar que o imaginário feminino presente na obra de Alberto Pimenta surge em perfeita consonância com o registo satirizante e crítico a que o poeta desde sempre nos habituou. Através da desconstrução dos estereótipos associados à figura da mulher, Pimenta apresenta-nos uma panóplia de representações altamente controversas para a época. Se por um lado nos deparamos com figurações de sujeitos desejantes, erotizados corporeamente com o objetivo de empreender uma ação reivindicativa de libertação sexual, por outro confrontamo-nos com uma desfiguração violenta de qualquer delicadeza secularmente associada à fisionomia da mulher. Descortinadoras de vícios e estigmas, as figuras femininas apresentadas pelo poeta surgem como mediadoras de uma crítica a um quotidiano em que a corrupção e a ausência de valores se revelam tangíveis. Por outras palavras, encontramo-nos perante figuras que denunciam um mundo no qual, como o próprio poeta escreveu:

Ninguém tem nada a esconder/nada

A não ser enfim o sexo.

Mas tem de o esconder de maneira tal

Que todos o possam reconhecer.

Ninguém tem nada a esconder/nada

A não ser enfim a mulher. 


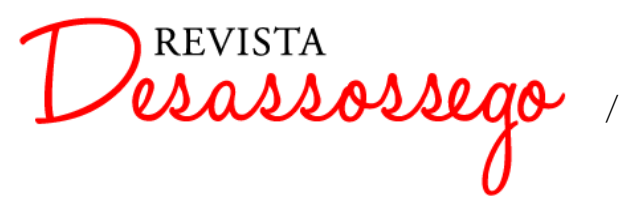

DESASSOSSEGO $17 \quad$ JUN/2017 | ISSN 2175-3180

DOI: http://dx.doi.org/10.11606/issn.2175-3180.v9i17p183-197

Mas tem de a esconder de maneira tal

Que todos a possam embevecer. (PIMENTA, 1973, p. 46)

\section{Referências}

AMARAL, Ana Luísa. "Do Centro e da Margem: Escrita do Corpo em Escritas de Mulheres". Cadernos de Literatura Comparada, Porto, n. 8/9, p. 105-121, 2003.

ARAGÃO, António. "a poesia começa onde o ar acaba”. In: Hatherly, Ana e E. M. De Melo e Castro. PO.EX: Textos teóricos e documentos da Poesia Experimental Portuguesa. Lisboa: Moraes Editores, 1981, p. 39.

BATAILLE, Georges. O Erotismo. Trad. João Bénard da Costa. Lisboa: Antígona, 1988.

EDFELDT, Chatarina. Uma bistória na História: Representações da Autoria na História da Literatura Portuguesa do século XX. Montijo: Câmara Municipal do Montijo, 2006.

GORJÃO, Vanda. "Oposição feminina (?), oposição feminista ao Estado Novo”, in: Amâncio, Lígia. O Longo Caminho das Mulheres: Feminismos - 80 Anos Depois. Lisboa: Dom Quixote, 2007, p. 108-123.

HATHERLY, Ana. "Situação da Vanguarda em Portugal. A Propósito dum Livro de Alberto Pimenta". Colóquio Letras, Lisboa, n. 45, p. 57-61, 1978.

HAYSOM, Peter. Mapeando as "margens de areia": políticas de localização em Novas Cartas Portuguesas. Dissertação de Mestrado em Estudos Literários, Culturais e Interartes. Porto: Faculdade de Letras da Universidade do Porto, 2016.

MELO E CASTRO, E. M. de. O fim visual do século XX. São Paulo: Editora da Universidade de São Paulo, 1993.

NOGUEIRA, Carlos. "Da Irreverência como Princípio Estético ou a Poesia de Alberto Pimenta". Separata de Dedalus, n. 9, p. 427-458, 2004. . "Sátira e Libertação em Alberto Pimenta". Metamorfoses, n. 6, p. 268-272, 2005.

PAZ, Octavio. "Erotismo: para uma definição (I)". In: Saraiva, Arnaldo. O que é o erotismo? Lisboa: Presença, 1979, p. 21-27.

PIMENTA, Alberto. O labirintodonte. Coimbra: Edição de Autor, 1970. Os entes e os contraentes. Coimbra: Edição de Autor, 1971. . Corpos estranhos. Coimbra: Edição de Autor, 1973. 
- Ascensão de dez gostos à boca. Coimbra: Edição de Autor, 1977.

. A metáfora sinistra. Lisboa: Quimera, 1989.

RAMALHO, Maria Irene. "Não é preciso inventar". Jornal de Leiria, Leiria, p. 7-11, 20-032003.

ROMERO-BUJ, Sebastián. “O erotismo e a literatura”. In: Saraiva, Arnaldo. O que é o erotismo? Lisboa: Presença, 1979, p. 145-163. 